\title{
Dados de estação meteorológica oficial subestimam o estresse por calor em bovinos leiteiros criados em ambiente tropical
}

P.K.M. Brettas
https://orcid.org/0000-0003-2294-6852 M.R.B.M. Nascimento

https://orcid.org/0000-0003-4324-5262 E.C. Guimarães

https://orcid.org/0000-0001-8328-9687

\author{
[Official meteorological station data underestimate the heat stress on dairy cattle in a \\ tropical environment]
}

P.K.M. Brettas, E.C. Guimarães, M.R.B.M. Nascimento

Universidade Federal de Uberlândia - Uberlândia, MG

\begin{abstract}
RESUMO
Determinaram-se os valores de temperatura do ar, umidade relativa e índice de temperatura e umidade (ITU) de uma propriedade rural de produção de leite a pasto e da estação meteorológica oficial mais próxima, confrontando-os. Na fazenda, as leituras dos dados foram registradas por uma estação meteorológica automática, a cada cinco minutos, de fevereiro de 2015 a setembro de 2016. Depois, calcularam-se a média por hora e o ITU horário. Selecionaram-se os valores diários mínimo, médio e máximo. O mesmo foi feito com os dados da estação meteorológica oficial, que foram horários. As temperaturas mínima e média na estação meteorológica foram maiores que na fazenda durante todo o período experimental e em 16 meses, respectivamente. A temperatura máxima da propriedade rural foi maior que a da estação em seis meses. Já a umidade relativa mínima, a média e a máxima da estação meteorológica foram inferiores às da fazenda. O ITU mínimo foi maior na estação oficial e o ITU máximo superior na fazenda em todos os meses. Por fim, o número de dias com um ITU máximo igual ou superior ao ITU crítico foi maior na fazenda. Assim, dados da estação meteorológica oficial subestimam o estresse por calor.
\end{abstract}

Palavras-chave: conforto térmico, estresse térmico, gado leiteiro, índice de temperatura e umidade

\begin{abstract}
The values of air temperature, relative humidity and Temperature Humidity Index (THI) of one pasturebased milk production farm and from the nearest official weather station were confronted. At the farm, data readings were recorded by an automatic weather station, every five minutes, from February 2015 to September 2016. Then, the hourly average and hourly THI were calculated. The minimum, average, and maximum daily values were selected. The same was done with data from the official hourly weather station data. The minimum and mean temperature in the meteorological station were higher than on the farm throughout the experimental period and in 16 months, respectively. The maximum temperature of the rural property was greater than that of the station in six months. Meanwhile, the minimum, average, and maximum relative humidity of the meteorological station were lower than those of the farm. The minimum THI was higher at the official station and the maximum THI was higher at the farm in every month. Finally, the number of days with a maximum THI equal to or greater than the critical THI was greater on the farm. Thus, official weather station data underestimate the heat stress.
\end{abstract}

Keywords: thermal comfort, thermal stress, dairy cattle, temperature humidity index

\section{INTRODUÇÃO}

O bovino criado a pasto está sob efeito das condições meteorológicas; associar os vários fatores do ambiente térmico em um único valor

Recebido em 20 de dezembro de 2017

Aceito em 26 de março de 2018

E-mail: pattybrettas@yahoo.com.br auxilia na tomada de decisão quanto aos efeitos do estresse térmico. Assim, o índice de temperatura e umidade (ITU), que avalia o efeito da temperatura e umidade concomitantemente, é amplamente empregado na avaliação do estresse por calor no gado leiteiro e pode ser calculado por distintas equações (Bohmanova et al., 2007). 
A obtenção desses dados pode ocorrer em estações meteorológicas oficiais ou na propriedade rural, mas muitos consideram que a primeira opção seja mais fácil e mais barata (Shock et al., 2016). Dessa forma, vários estudos recentes sobre estresse por calor baseiam-se em variáveis do ambiente térmico oriundas das estações meteorológicas oficiais mais próximas aos locais de estudo (Ludovico et al., 2015; Vitali et al., 2015; Mendonça et al., 2017).

Porém, as mensurações de temperatura e de umidade do ar na fazenda requerem apenas um termo-higrômetro, equipamento encontrado facilmente e com preço acessível (Neves et al., 2015). Adicionalmente, pesquisas atuais e realizados em regiões temperadas, como Schuller et al. (2013), na Alemanha, Scanavez et al. (2016), nos Estados Unidos, e Shock et al. (2016), no Canadá, mostraram que os dados das estações meteorológicas oficiais subestimaram o efeito do estresse por calor a que os animais estavam suscetíveis.

Em tais estudos, contudo, as variáveis do ambiente térmico da propriedade rural não foram avaliadas no pasto, mas, sim, dentro de instalações, pois os animais eram confinados no sistema freestall ou tiestall. Dessa forma, mais pesquisas são necessárias para avaliar se as condições meteorológicas a pasto e em regiões tropicais também diferem dos dados de uma estação meteorológica oficial próxima, assim como ocorreu nas criações em confinamento (Schuller et al., 2013).

Portanto, objetivou-se comparar dados de temperatura ambiente, umidade do ar e índice de temperatura e umidade (ITU), obtidos em uma propriedade rural, em região tropical com sistema de criação de bovinos leiteiros a pasto, com os da estação meteorológica oficial mais próxima, com a finalidade de avaliar o estresse por calor.

\section{MATERIAL E MÉTODOS}

A Fazenda do Câmpus Glória (869m de altitude, $18^{\circ} 55^{\prime} 03,5^{\prime}$ ' de latitude sul e $48^{\circ} 15^{\prime} 31,2$ ' ' de longitude oeste) da Universidade Federal de Uberlândia (UFU), localizada no município de Uberlândia, MG, Brasil, foi a propriedade rural na qual foram obtidos os dados do ambiente térmico e onde os animais eram criados a pasto.
Já os dados referentes à estação meteorológica oficial mais próxima foram cedidos pelo Laboratório de Climatologia e Recursos Hídricos do Instituto de Geografia da UFU/Estação Meteorológica de Observação de Superfície Automática do INMET (Instituto Nacional de Meteorologia) (938m de altitude, $18^{\circ} 56^{\prime} 40,9^{\prime}$ ', de latitude sul e $48^{\circ} 12^{\prime}$ 51,7' ' de longitude oeste), localizada no Câmpus Santa Mônica da UFU, próximo à área central da cidade e a aproximadamente $5,5 \mathrm{~km}$ da propriedade avaliada.

Os valores de temperatura do ar e de umidade relativa foram obtidos durante 20 meses: de 05 de fevereiro de 2015 a 30 de setembro de 2016, correspondendo a 607 dias. $\mathrm{Na}$ fazenda, as leituras foram feitas por uma estação meteorológica automática, com sensores e datalogger $\mathrm{Hobo}^{\circledR}$, instalada no pasto, a $1,0 \mathrm{~m}$ do solo e em uma localização na pastagem que garantiu uma distância segura para que não houvesse a interferência de outras culturas. Os sensores possuíam proteção para que a temperatura e a umidade pudessem ser medidas na sombra, protegidos da chuva e do vento. Os dados foram transferidos para um computador por meio da conexão USB a cada cinco ou seis meses.

O ITU foi calculado pela equação do National Research Council (A guide..., 1971), que, segundo Bohmanova et al. (2007), foi desenvolvida para avaliar o estresse térmico em animais criados em locais abertos:

$$
I T U=(1,8 T a+32)-(0,55-0,0055 U R)(1,8 T a-26),
$$

em que: $\mathrm{T}_{\mathrm{a}}$ : temperatura de bulbo seco $\left({ }^{\circ} \mathrm{C}\right) \mathrm{e}$ UR: umidade relativa $(\%)$.

As leituras feitas na fazenda, por serem a cada cinco minutos, foram inicialmente convertidas em dados horários médios de temperatura do ar e umidade relativa, para, então, serem calculados os valores horários do ITU. Assim, foram selecionados os valores diários mínimo, médio e máximo da temperatura, da umidade relativa e do ITU, calculados com os dados da propriedade rural.

O mesmo cálculo (valores diários mínimo, médio e máximo) foi feito com as leituras de temperatura do ar, de umidade relativa e, 
posteriormente, do ITU, oriundas da estação meteorológica oficial, que foram horárias. As estações automáticas do INMET coletam as informações meteorológicas a cada minuto e depois, a cada hora, integralizam-nas e as disponibilizam para serem transmitidas, via satélite ou telefonia celular, para a sede do INMET, em Brasília.

Para cada mês, realizaram-se as avaliações dos valores diários de ITU separadamente: ITU diário mínimo, médio e máximo. Eles foram submetidos ao teste de normalidade de Kolmogorov-Smirnov, e os dados que não apresentaram uma distribuição normal foram comparados pelo teste de Mann-Whitney (teste U). Já aqueles com distribuição normal passaram pelo teste de Levene para a avaliação das variâncias, e as suas médias mensais foram comparadas pelo teste t-Student. Todos os testes foram realizados com $5 \%$ de significância e também foram aplicados à temperatura do ar e à umidade relativa. As análises estatísticas foram executadas utilizando-se Action $^{\circledR} 2.9$ e no SPSS $^{\circledR}$.

\section{RESULTADOS E DISCUSSÃO}

A temperatura mínima oriunda da estação meteorológica oficial foi superior à da propriedade rural em todos os meses (Fig. 1). A temperatura mínima geralmente é registrada à noite, e o seu valor mais elevado na cidade, assim como ocorreu no presente estudo, pode ser explicado principalmente pelo fato de o calor retido pelos edifícios, pelas construções e pelos pavimentos ser dissipado lentamente após o pôr do sol (Gartland, 2010). Em contrapartida, em áreas abertas como as pastagens, a grama resfria rapidamente ao anoitecer, em especial por apresentar um baixo calor específico (Landsberg, 2006).

O aumento da temperatura em áreas urbanas, conhecido como "ilhas de calor", deve-se a vários fatores, como a maior capacidade térmica dos materiais, o calor gerado pelos habitantes e pelas atividades urbanas e a diminuição das perdas de calor por irradiação noturna (Landsberg, 2006). Entretanto, Schuller et al. (2013), que trabalharam apenas com valores médios, obtiveram maior temperatura ambiente na propriedade rural, especialmente nos meses mais frios, justificando tal resultado com a maior produção de calor pelas vacas no frio, as quais estavam confinadas em sistema freestall.

Em 16 meses da pesquisa, os maiores valores de temperatura média foram observados na estação meteorológica oficial em comparação aos da fazenda, não diferindo nos outros quatro meses (Fig. 2). Esse resultado possivelmente se relaciona com o fenômeno citado acima, "ilhas de calor", em que distintos locais da área urbana tendem a apresentar temperaturas médias mais elevadas que a zona rural circundante (Gartland, 2010).

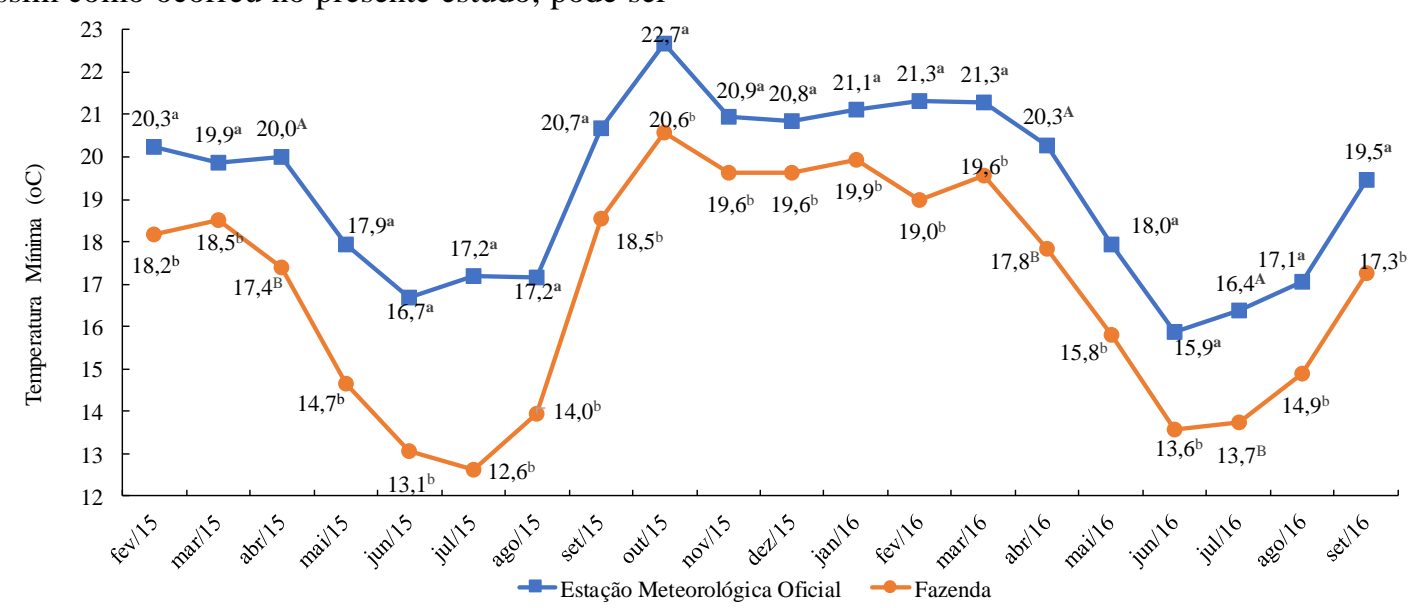

Figura 1. Médias da temperatura do ar mínima $\left({ }^{\circ} \mathrm{C}\right)$ calculadas pelos dados da estação meteorológica oficial mais próxima e da propriedade rural (Fazenda Glória - Universidade Federal de Uberlândia), de fevereiro de 2015 a setembro de 2016, Uberlândia, MG, Brasil. Dentro de cada mês, médias seguidas por letras minúsculas diferem entre si pelo teste de t-Student, e seguidas por letras maiúsculas diferem pelo teste de Mann-Whitney $(\mathrm{P}<0,05)$. 


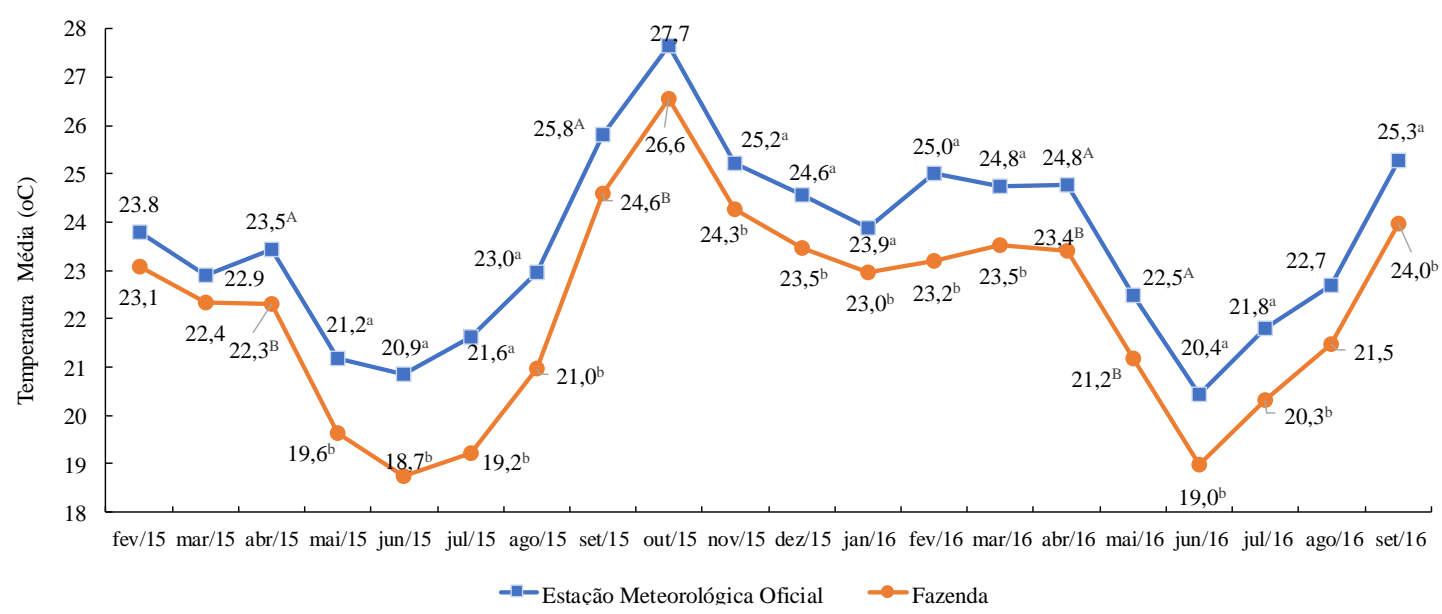

Figura 2. Médias da temperatura do ar média $\left({ }^{\circ} \mathrm{C}\right)$ calculadas pelos dados da estação meteorológica oficial mais próxima e da propriedade rural (Fazenda Glória - Universidade Federal de Uberlândia), de fevereiro de 2015 a setembro de 2016, Uberlândia, MG, Brasil.

A temperatura máxima não diferiu entre os valores da estação meteorológica e da fazenda em 14 meses, porém, nos demais seis meses, os maiores valores foram os da propriedade rural, em torno de $2^{\circ} \mathrm{C}$ a mais (Fig. 3). A temperatura superior no campo pode ser explicada, em parte, pela maior radiação solar, uma vez que na cidade a poluição e as edificações bloqueiam os raios solares.

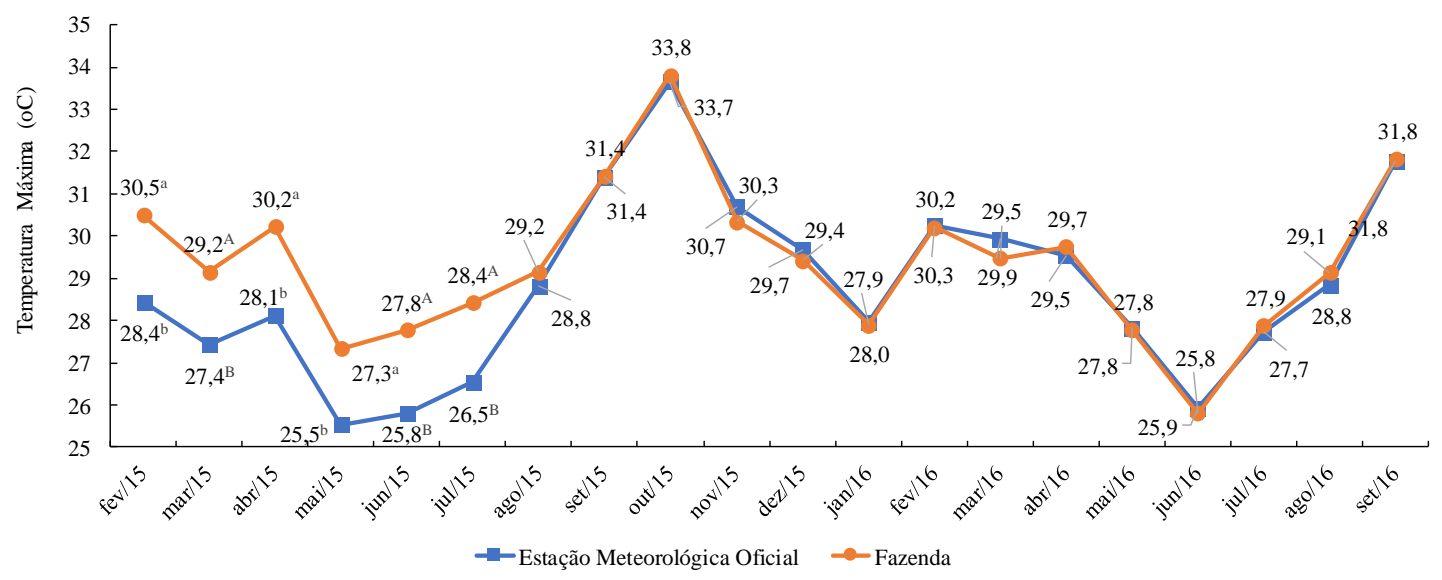

Figura 3. Médias da temperatura do ar máxima $\left({ }^{\circ} \mathrm{C}\right)$ calculadas pelos dados da estação meteorológica oficial mais próxima e da propriedade rural (Fazenda Glória - Universidade Federal de Uberlândia), de fevereiro de 2015 a setembro de 2016, Uberlândia, MG, Brasil.

Ao comparar o espaço urbano e o rural no interior de São Paulo, Brasil, Amorim (2012) observou que, durante a manhã e no horário de maior incidência de radiação solar, a zona rural foi a que apresentou as temperaturas mais elevadas, assim como ocorreu na presente pesquisa. Também Schuller et al. (2013) registraram valores mais elevados da temperatura do ar nas instalações da fazenda apenas durante os meses mais quentes e relacionaram tal resultado com falhas na construção e uso incorreto dos ventiladores e aspersores. Shock et al. (2016), que trabalharam apenas com os meses de verão, também registraram as maiores temperaturas nas instalações da propriedade rural.

Nesse aspecto, Landsberg (2006) afirmou que, apesar do fenômeno "ilhas de calor", há uma preponderância de máximas no campo, pois, nas 
cidades, o nível das maiores temperaturas está acima dos telhados e ainda há uma menor radiação solar em razão das construções e da névoa seca resultante da grande quantidade de gases, partículas sólidas e aerossóis lançados no ar pelas indústrias e pelo trânsito intenso de veículos. Mendonça e Dubreuil (2005) também atribuíram o maior aquecimento das áreas rurais à maior radiação sobre elas. Aliás, o aquecimento ao longo do dia ocorre mais rapidamente na zona rural, pois é mais livre de construções, especialmente nos pastos, os quais recebem os raios solares diretamente desde o nascer do sol e apresentam um elevado coeficiente de reflexão, devolvendo o calor para a atmosfera de maneira mais rápida (Viana e Amorim, 2008).

Esse coeficiente de reflexão da superfície para a radiação de onda curta corresponde ao conceito de albedo da superfície ou poder refletor da superfície (Arya, 1998). Lima (1996) relatou, por exemplo, que as florestas apresentam um albedo médio de 10 a 12\%; já a vegetação rasteira, como a pastagem e a maioria das culturas agrícolas, exibe albedo médio da ordem de 18 a $25 \%$. Logo, o pasto tende a não proporcionar locais confortáveis durante as horas de radiação mais intensa (Gomes et al., 2016). O mesmo fato não tende a ocorrer nas cidades por causa do "efeito sombra" exercido pelas construções e pela presença de grande quantidade de partículas de poluição, que interceptam os raios solares (Amorim, 2012).

Por fim, uma cidade pode apresentar áreas com temperaturas distintas, conforme as variações no uso do solo urbano. Essas variações térmicas podem chegar a $7^{\circ} \mathrm{C}$ e ocorrem principalmente entre os espaços livres, os vegetados e as áreas construídas (Eliasson, 2000). Assim, a localização da estação meteorológica na zona urbana pode influenciar nos valores dos dados meteorológicos, podendo ser distintos de outros pontos da cidade e da zona rural ao redor.

A umidade relativa mínima, a média e a máxima da estação meteorológica foram inferiores às da fazenda em todos os meses, exceto a máxima de março de 2015, que foi superior na estação, e a máxima de abril de 2015, que não diferiu (Fig. 4, 5 e 6). As cidades têm uma umidade menor em virtude das elevadas temperaturas médias, da pouca vegetação, do rápido escoamento da precipitação pelo sistema de drenagem e da expansão das superfícies impermeáveis, como os telhados e as ruas asfaltadas (Landsberg, 2006). Além disso, a pastagem contribui para a infiltração e retenção da água da chuva, aumentando a umidade nas áreas rurais (Gomes et al., 2016).

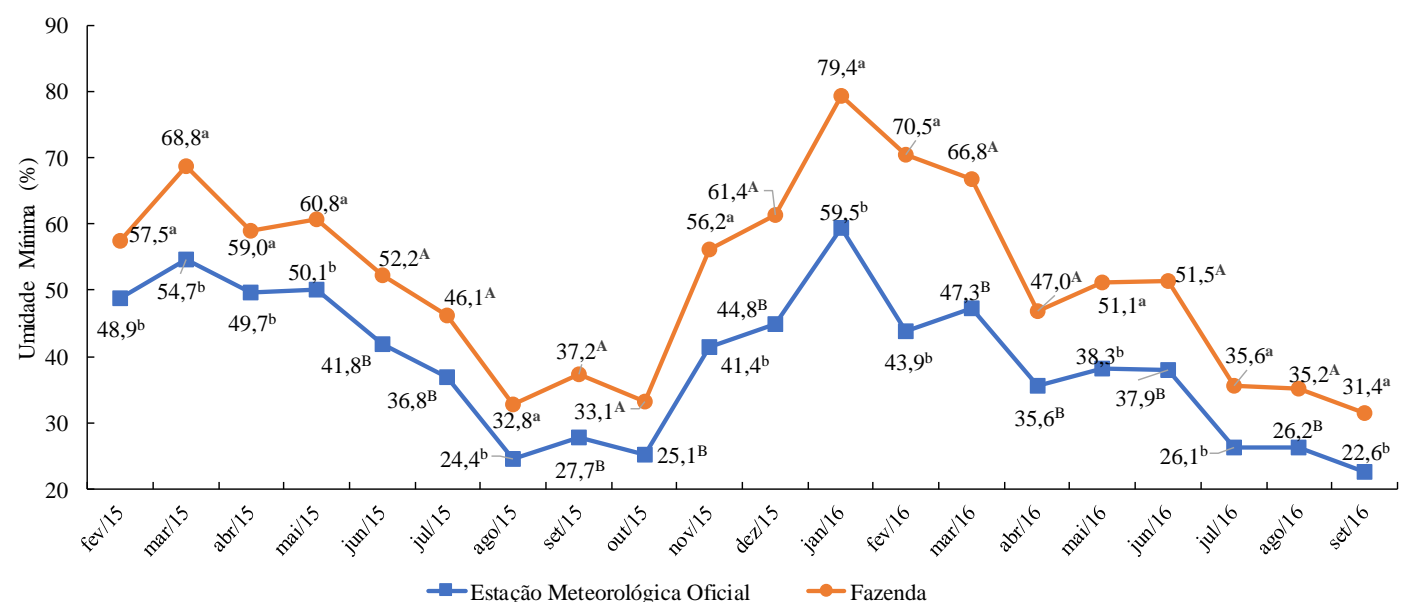

Figura 4. Médias da umidade relativa mínima (\%) calculadas pelos dados da estação meteorológica oficial mais próxima e da propriedade rural (Fazenda Glória - Universidade Federal de Uberlândia), de fevereiro de 2015 a setembro de 2016, Uberlândia, MG, Brasil. 


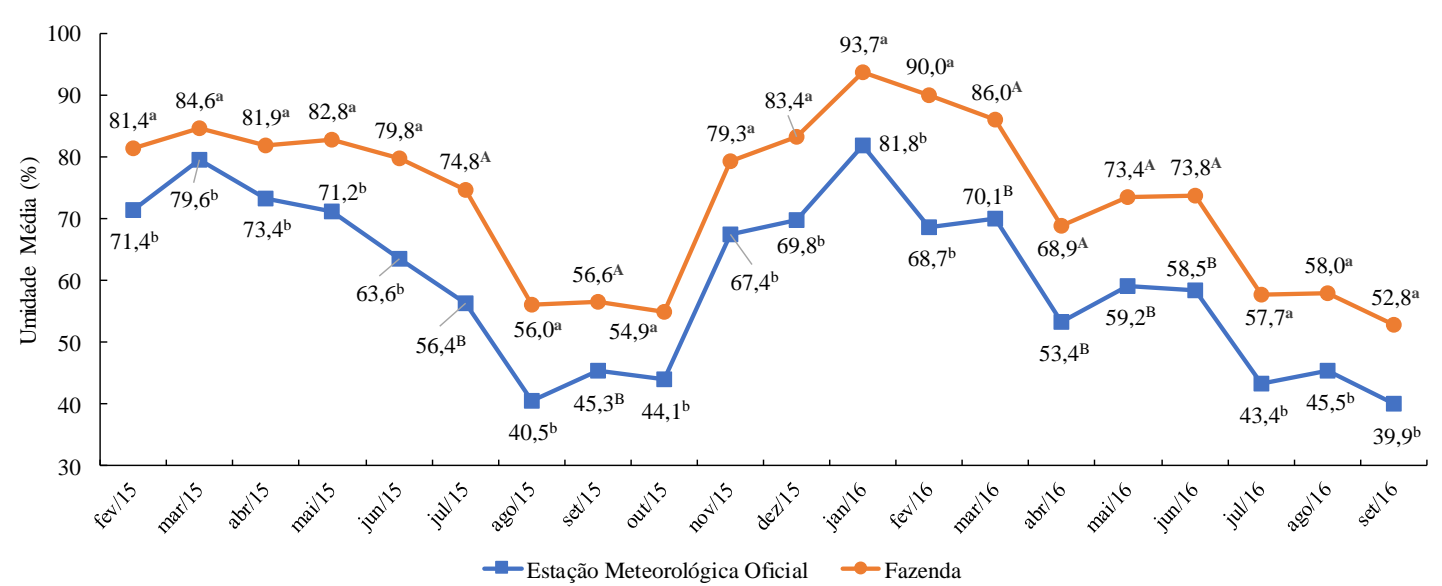

Figura 5. Médias da umidade relativa média (\%) calculadas pelos dados da estação meteorológica oficial mais próxima e da propriedade rural (Fazenda Glória - Universidade Federal de Uberlândia), de fevereiro de 2015 a setembro de 2016, Uberlândia, MG, Brasil.

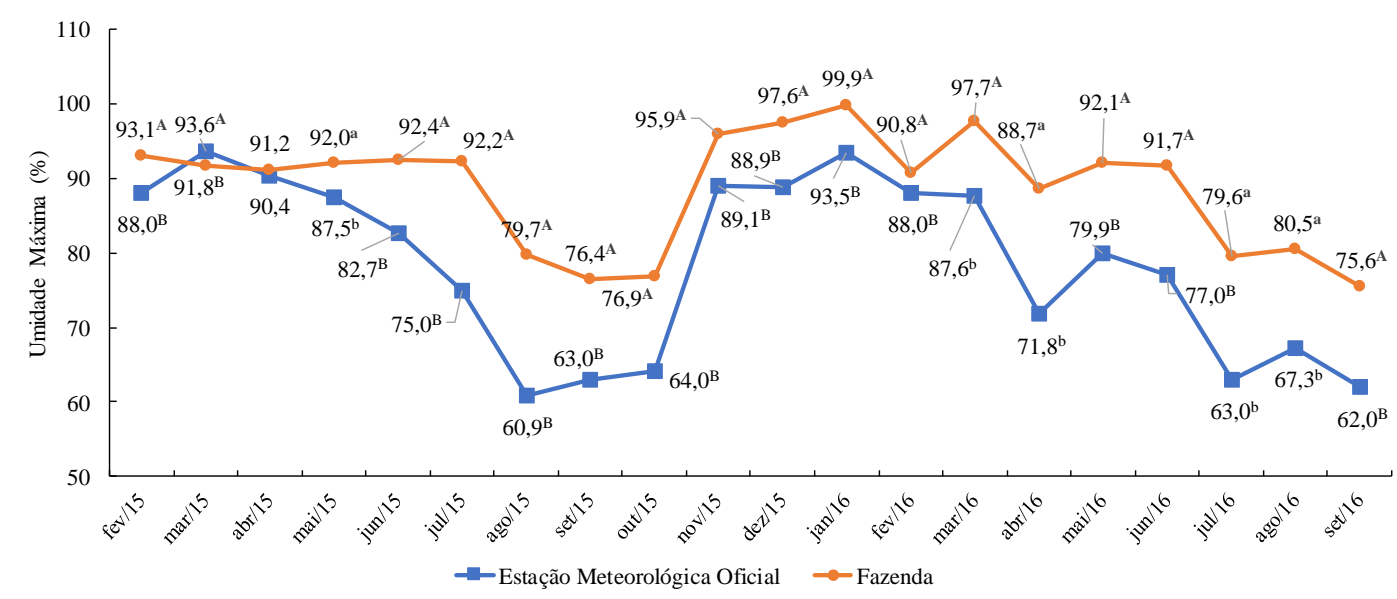

Figura 6. Médias da umidade relativa máxima (\%) calculadas pelos dados da estação meteorológica oficial mais próxima e da propriedade rural (Fazenda Glória - Universidade Federal de Uberlândia), de fevereiro de 2015 a setembro de 2016, Uberlândia, MG, Brasil.

No estudo de Schuller et al. (2013), nos meses mais quentes, os valores de umidade relativa oriundos da estação meteorológica oficial também foram inferiores aos da propriedade rural coletados dentro do galpão de criação de bovinos confinados. Os autores atribuíram esse fato à maior perda de água por evaporação pelas vacas associada à má ventilação no interior da construção (sistema freestall). Já Shock et al. (2016) notaram que os valores de umidade relativa variaram muito de acordo com o mês, ora foram maiores na fazenda, ora na estação meteorológica oficial.

O ITU médio da estação meteorológica oficial foi superior ao da fazenda em oito meses da pesquisa e não diferiu em 12 meses (Fig. 7). O ITU mínimo foi maior na estação meteorológica (Fig. 8) e o ITU máximo foi superior na propriedade rural nos 20 meses de avaliação (Fig. 9). No mês de fevereiro de 2016, por exemplo, em que não houve diferença nas temperaturas máximas oriundas da estação meteorológica oficial e da fazenda, o ITU máximo nesta última chegou a ser quatro unidades superior ao ITU máximo observado na estação oficial, o que, portanto, pode ser justificado pelos maiores valores de umidade relativa sempre registrados no campo. Schuller et al. (2013), nos meses mais quentes, também obtiveram os maiores valores do ITU nas instalações da propriedade rural (sistema 
freestall), com diferenças de três a quatro unidades.

Da mesma maneira, os valores mensais do ITU observados por Shock et al. (2016) foram maiores nas instalações da fazenda (sistemas freestall e tiestall) que na estação meteorológica oficial mais próxima nos quatro meses (verão) avaliados. Entretanto, a magnitude dessa diferença variou muito: 4,64 (ITU mínimo), 3,09 (ITU médio) e 1,74 (ITU máximo). Também é importante ressaltar que os pesquisadores avaliaram mais de uma estação meteorológica e concluíram que a distância entre estas e a propriedade rural não influenciou nas diferenças das variáveis ambientais e do ITU.

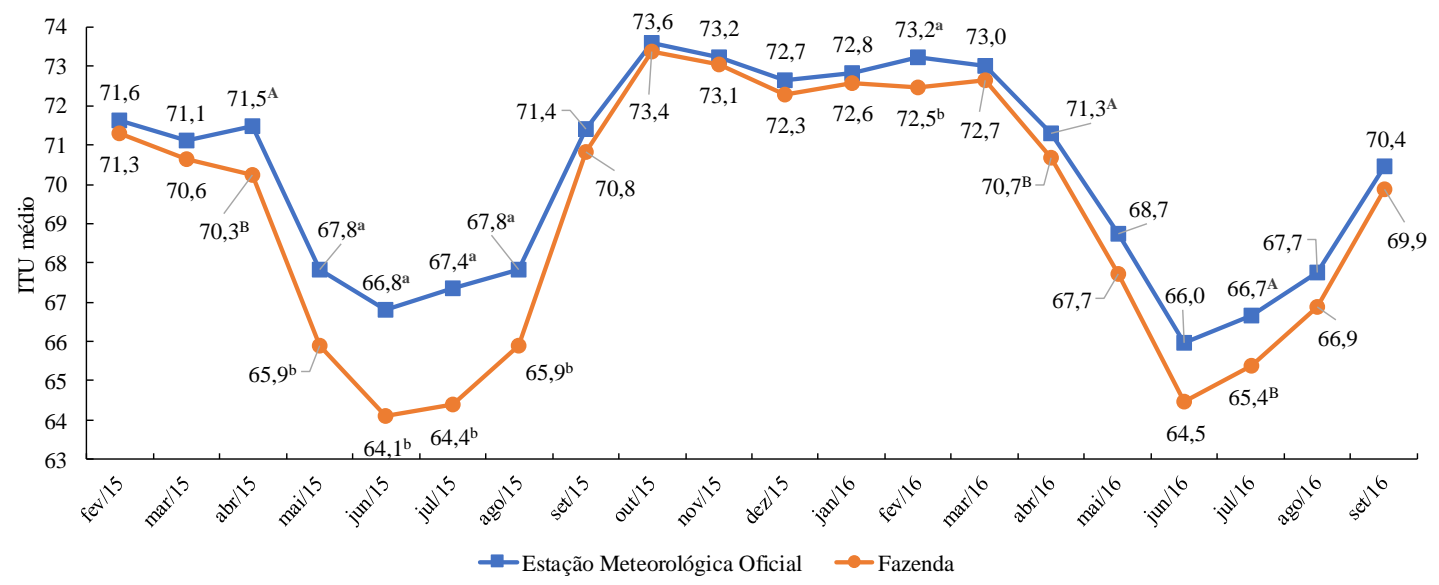

Figura 7. Médias do índice de temperatura e umidade (ITU) médio calculadas pelos dados da estação meteorológica oficial mais próxima e da propriedade rural (Fazenda Glória - Universidade Federal de Uberlândia), de fevereiro de 2015 a setembro de 2016, Uberlândia, MG, Brasil.

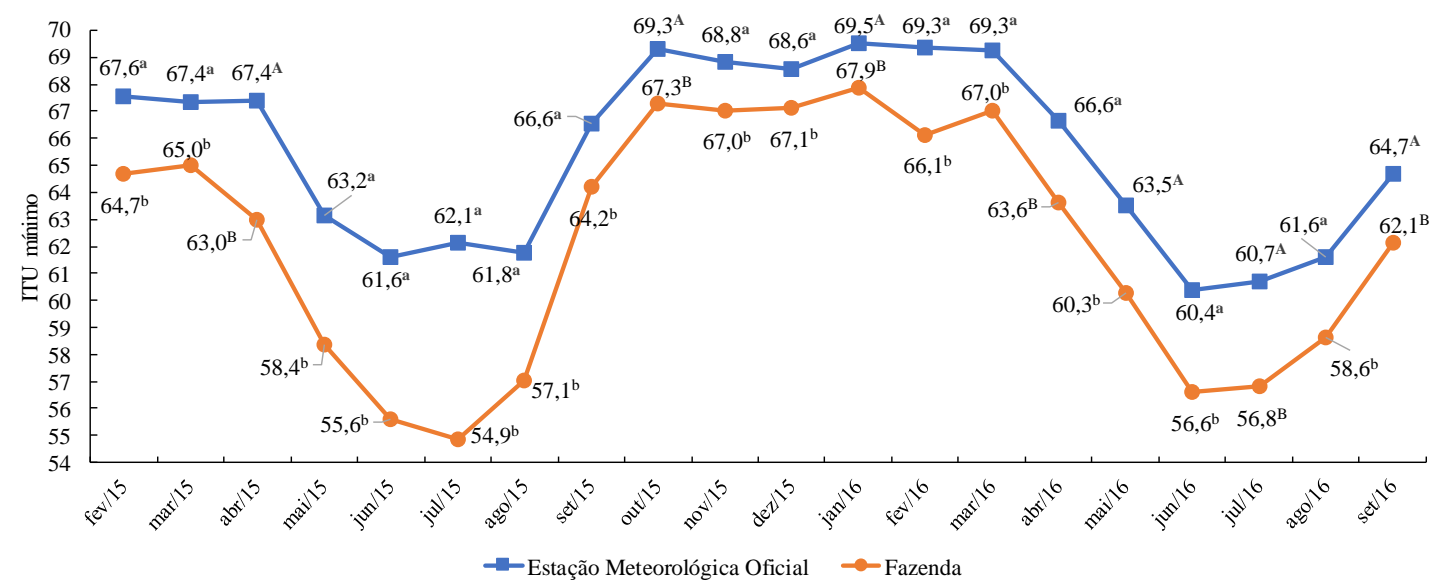

Figura 8. Médias do índice de temperatura e umidade (ITU) mínimo calculadas pelos dados da estação meteorológica oficial mais próxima e da propriedade rural (Fazenda Glória - Universidade Federal de Uberlândia), de fevereiro de 2015 a setembro de 2016, Uberlândia, MG, Brasil. 


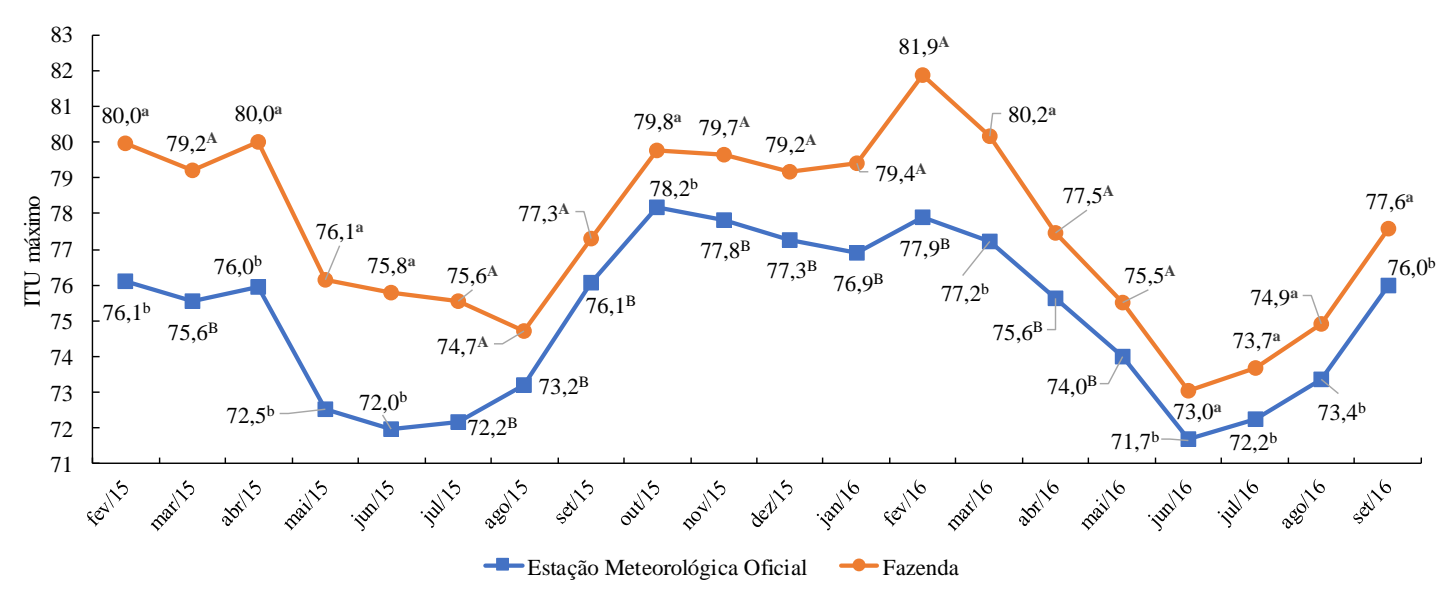

Figura 9. Médias do Índice de Temperatura e Umidade (ITU) máximo calculadas pelos dados da estação meteorológica oficial mais próxima e da propriedade rural (Fazenda Glória - Universidade Federal de Uberlândia), de fevereiro de 2015 a setembro de 2016, Uberlândia, MG, Brasil.

Quanto ao ITU crítico, que caracteriza o início do estresse por calor, Ravagnolo et al. (2000) avaliaram 15.012 vacas da raça Holandês com uma produção que variou de 9,1 a $58,5 \mathrm{~kg} \cdot \mathrm{dia}^{-1}$, em 251 fazendas dos Estados Unidos, e concluíram que ela permanecia constante até um ITU igual a 72. A partir desse valor, a queda para cada unidade a mais de ITU foi de $0,2 \mathrm{~kg}$ de leite. Já Zimbelman et al. (2009), também nos Estados Unidos, avaliaram 100 vacas confinadas da raça Holandês e de elevada produção (mais de $35 \mathrm{~kg} \cdot \mathrm{dia}^{-1}$ ) e observaram que as quedas na produtividade passaram a ser maiores após 17 horas de exposição a um ambiente térmico com um ITU igual ou superior a 68.

$\mathrm{Na}$ presente pesquisa, quando se considerou o valor crítico de ITU como 68 , o número de dias em que o ITU máximo foi igual ou superior a 68 foi muito próximo quando se compararam os dados oriundos da fazenda com os originários da estação meteorológica oficial (Tab. 1). Porém, quando o ITU crítico foi considerado igual a 72, tal diferença começou a se acentuar, pois os dados oriundos da estação meteorológica não detectaram estresse por calor em $16,64 \%$ dos dias avaliados (101 dias) e os da fazenda em apenas 6,1\% (37 dias). Schuller et al. (2013), que também consideraram o ITU crítico de 72 , verificaram que dos 756 dias avaliados, o ITU foi superior a 72 em 75 dias $(9,92 \%)$ na estação meteorológica oficial e em 162 dias $(21,42 \%)$ na fazenda, uma diferença de 87 dias $(11,5 \%$ dos dias avaliados).

Tabela 1. Número, diferença e percentual de dias em que o ITU máximo foi igual ou superior ao ITU crítico na propriedade rural (Fazenda Glória - Universidade Federal de Uberlândia) e na estação meteorológica oficial (EM) mais próxima, de fevereiro de 2015 a setembro de 2016 (607 dias), Uberlândia, MG, Brasil

\begin{tabular}{cccccc}
\hline \multirow{2}{*}{ Local } & $68^{*}$ & $72 * *$ & $76 * * *$ & $77 * * *$ & $79 * * *$ \\
\cline { 2 - 5 } & $602(99,17 \%)$ & $570(93,90 \%)$ & $427(70,34 \%)$ & $368(60,62 \%)$ & $222(36,57 \%)$ \\
Fazenda & $598(98,51 \%)$ & $506(83,36 \%)$ & $282(46,45 \%)$ & $183(30,14 \%)$ & $24(3,95 \%)$ \\
EM & $4(0,65 \%)$ & $64(10,54 \%)$ & $145(23,88 \%)$ & $185(30,47 \%)$ & $198(32,61 \%)$ \\
Diferença &
\end{tabular}

* Valor indicado por Zimbelmam et al. (2009). **Valor indicado por Ravagnolo et al. (2000). ***Valores indicados por Azevedo et al. (2005) para vacas 7/8, 3/4 e 1/2 Holandês-Zebu, respectivamente.

Ao se interpretarem os valores críticos do ITU, é necessário cautela, pois a maioria deles são válidos para regiões temperadas e para vacas Holandesas menos tolerantes ao calor, condição em que foram determinados (Fonsêca et al., 2016). Portanto, para os animais mais adaptados às regiões tropicais, esses valores críticos podem 
estar superestimados e fornecendo uma interpretação incorreta do ambiente térmico.

Assim, se forem considerados os resultados da pesquisa com animais mestiços desenvolvida no Brasil pela Embrapa Gado de Leite (Azevedo et al., 2005), tem-se como valores críticos de ITU baseados na frequência respiratória das vacas 1/2, 3/4 e 7/8 Holandês-Zebu, respectivamente, 79, 77 e 76. Com base nesses valores de ITU iguais a 76, 77 e 79, os dados oriundos da estação meteorológica não detectaram estresse por calor em $53,55 \%$ dos dias avaliados (325 dias), 69,86\% (424 dias) e 96,05\% (583 dias); já os dados obtidos na fazenda não registraram estresse térmico em apenas 29,66\% dos dias analisados (180 dias), 39,38\% (239 dias) e $63,43 \%$ (385 dias), respectivamente.

\section{CONCLUSÕES}

Os dados provenientes da estação meteorológica oficial subestimam o estresse por calor a que os bovinos criados a pasto em regiões tropicais estão susceptíveis, o que se acentua à medida que é tomado como referência um valor crítico maior de ITU. Assim, as medidas do ambiente térmico coletadas na propriedade rural são as que representam a condição térmica a que os animais estão expostos e devem ser priorizadas.

\section{AGRADECIMENTOS}

Ao Prof. Dr. Luiz Antônio de Araújo, do Instituto de Geografia da Universidade Federal de Uberlândia, por prontamente fornecer os dados meteorológicos coletados na Fazenda do Câmpus Glória.

\section{REFERÊNCIAS}

A GUIDE to environmental research on animals. Washington: National Academy of Science/NRC, 1971. 374p.

AMORIM, M.C.C.T. A produção do clima urbano em ambiente tropical: o exemplo de Presidente Prudente/SP. Rev. GeoNorte, v.3, p.52-64, 2012.

ARYA, S.P. Introduction to micrometeorology. North Carolina: International Geophysics Series - Academic Press, 1998. 33p.
AZEVEDO, M.; PIRES, M.F.A.; SATURNINO, H.M. et al. Estimativa de níveis críticos superiores do índice de temperatura e umidade para vacas leiteiras 1/2, 3/4, 7/8 Holandês-Zebu em lactação. Rev. Bras. Zootec., v.34, p. 20002008, 2005.

BOHMANOVA, J.; MISZTAL, I.; COLE, J.B. Temperature-humidity indices as indicators of milk production losses due to heat stress. $J$. Dairy Sci., v.90, p.1947-1956, 2007.

ELIASSON, I. The use of climate knowledge in urban planning. Landscape Urban Plan., v.48, p.31-44, 2000.

FONSÊCA， V.D.F.C.; CÂNDIDO, E.P.; GONZAGA NETO, S.G. et al. O. Thermoregulatory responses of sindhi and guzerat heifers under shade in a tropical environment. Semin. Ciênc. Agrar., v.37, p.43274338, 2016.

GARTLAND, L. Ilhas de calor: como mitigar zonas de calor em áreas urbanas. São Paulo: Oficina de Textos, 2010. 248p.

GOMES, M.R.; MARTIN, E.S.; AMORIM, M.C.T. Distribuição das temperaturas superficiais intraurbana em Caicó/RN. Formação, v.3, p.286-300, 2016.

LANDSBERG, H.E. O clima das cidades. Rev. Dep. Geogr. Univ. São Paulo, v.18, p.95-111, 2006.

LIMA, W.P. Impacto ambiental do eucalipto. 2.ed. São Paulo: Universidade de São Paulo, 1996. 301p.

LUDOVICO, A.; MAION, V.B.; BRONKHORST, D.E. et al. Perdas na produção e qualidade do leite devido contagem de células somáticas no leite e estresse térmico de vacas da raça Holandesa em clima temperado. Semin. Ciênc. Agrar., v.36, p.3455-3470, 2015.

MENDONÇA, F.; DUBREUIL, V. Termografia de superfície e temperatura do ar na RMC (região metropolitana de Curitiba/PR). Rev. Ra'e Ga - Espaço Geogr. Anál., v.9, p.25-35, 2005.

MENDONÇA, L.G.D.; MANTELO, F.M.; STEVENSON, J.S. Fertility of lactating dairy cows treated with gonadotropin-releasing hormone at AI, 5 days after AI, or both, during summer heat stress. Theriogenology, v.91, p.916, 2017. 
NEVES, G.A.R.; NOGUEIRA, J.S.; BIUDES, M.S. et al. Desenvolvimento e calibração de um termohigrômetro para uso em pesquisas de micrometeorologia, agrometeorologia e clima. Bol. Univ. Fed. Paraná, Geogr. Fis., v.8, p.136143, 2015.

RAVAGNOLO, O.; MISZTAL, I.; HOOGENBOOM, G. Genetic component of heat stress in dairy cattle, development of heat index function. $J$. Dairy Sci., v.83, p.2120-2125, 2000.

SCANAVEZ, A.; ROCHA, L.; VOELZ, B.E.; HULBERT, L. Evaluation of weather information from on-farm and meteorological stations to assess heat stress in dairy cows in Southwest Kansas. Kans. Agric. Exp. Stn., v.2, p.2-7, 2016.

SCHULLER, L.K.; BURFEIND, O.; HEUWIESER, W. Comparison of ambient temperature, relative humidity, and temperature-humidity index between on-farm measurements and official meteorological data. J. Dairy Sci., v.96, p.77317738, 2013.
SHOCK, D.A.; LeBLANC, S.J.; LESLIE, K.E. et al. Studying the relationship between on-farm environmental conditions and local meteorological station data during the summer. $J$. Dairy Sci., v.99, p.2169-2179, 2016.

VIANA, S.S.M.; AMORIM, M.C.C.T. Caracterização do clima urbano em Teodoro Sampaio/SP: uma introdução. Soc. Nat., v.20, p.19-42, 2008.

VITALI, A.; FELICI, A.; ESPOSITO, S. et al. The effect of heat waves on dairy cow mortality. J. Dairy Sci., v.98, p.4572-4579, 2015.

ZIMBELMAN, R.B.; RHOADS, R.P.; RHOADS, M.L. et al. A re-evaluation of the impact of temperature humidity index (THI) and black globe humidity index (BGHI) on milk production in high producing dairy cows. In: ANNUAL SOUTHWEST NUTRITION AND MANAGEMENT CONFERENCE, 24., 2009, Arizona. Proceedings... Arizona: University of Arizona, 2009. p.158-169. 